\title{
PROCESSO DE PROJETO EM EMPREENDIMENTOS IMOBILIÁRIOS: AVALIAÇÃO DE PROJETISTAS E CONSTRUTORES
}

\author{
Design process in real estate projects: evaluation of designers \\ and construction engineers
}

Kelma Pinheiro Leite', José de Paula Barros Neto', Marina Teixeira', Camila Claudino

RESUMO Este artigo apresenta os resultados da survey sobre o processo projetual em projetos imobiliários na cidade de Fortaleza, Brasil. O objetivo principal é descrever como projetistas e construtores avaliam o processo de projeto imobiliário, a fim de aprofundar a compreensão de suas expectativas e necessidades. A percepção dos profissionais ligados diretamente à produção de edificações é necessária para adaptação ao novo cenário de implantação de sistemas BIM. Além disso, nota-se que a migração para novos sistemas e o aumento da complexidade e da fragmentação do processo de projeto requerem novas visões. Como resultado, foram identificadas oportunidades de melhoria do processo de desenvolvimento de produto imobiliário. Este estudo baseou-se no referencial teórico da literatura sobre pensamento enxuto, lean design, processo de projeto e desenvolvimento de produtos imobiliários. Os dados foram coletados a partir da aplicação de 90 questionários preenchidos por projetistas e engenheiros de obra em incorporadoras e construtoras. As principais questões de insatisfação identificadas foram: retrabalho; planejamento deficiente do processo de desenvolvimento de produto imobiliário; os prazos estipulados e compatibilização.

PALAVRAS-CHAVE: Processo de projeto, Mercado imobiliário, Construção enxuta.

ABSTRACT This article presents the results of a research about the design process in real estate projects in Fortaleza, Brazil. The main objective is to describe how designers and construction engineers evaluate the design process, in order to improve the capability of understanding their expectations and needs. The perception of professionals directly linked to the production of buildings is important for the adaptation to the new BIM system deployment scenario. In addition, it is possible to note that the migration to new systems and the increase in complexity and fragmentation of the design process require new perspectives. As a result, opportunities to improve the real estate product development process were identified. This study was based on theoretical literature on lean thinking, lean design, design process, and development of real estate products. Data were collected from the application of 90 questionnaires fulfilled by designers and engineers working for developers and construction companies. The main issues of dissatisfaction identified were: rework; poor planning of real estate product development process; deadlines, and compatibility.

KEYWORDS: Design process, Real estate process, Lean construction.

\section{How to cite this article:}

LEITE, K. P.; BARROS NETO, J. P.; TEIXEIRA, M.; CLAUDINO, C. Processo de projeto em empreendimentos imobiliários: avaliação de projetistas e construtores. Gestão e Tecnologia de Projetos, São Paulo, v. 10, n. 2, p. 21-34, jul./ dez. 2015

http://dx.doi.org/10.11606/gtp.v10i2.102050

Fonte de financiamento: CAPES - Coordenação de Aperfeiçoamento de Pessoal de Nivel Superior Conflito de interesse: Declaram não haver Submetido em: 14 out. 2015 Aceito em: 23 out. 2015 


\section{INTRODUÇÃO}

Esta pesquisa aborda o processo de desenvolvimento de produto e o processo de projeto do mercado de incorporação imobiliária residencial multifamiliar vertical, sob a ótica de projetistas e construtores. O processo de projeto é um processo colaborativo de aprendizagem (KOWALTOWSKI et al., 2006). Daí a necessidade de contínua avaliação da percepção dos atores sobre o objeto e o processo de concepção e construção.

Tzortzopoulos (1999); Oliveira (2004); Andersen et al. (2005); Jorgensen (2006) e Kamedula (2009) citam que a maior parte das pesquisas do setor da construção civil são direcionadas à melhoria da qualidade na construção, priorizando o desenvolvimento de métodos de gestão da produção, novas tecnologias e racionalização de sistemas construtivos, porém não se tem observado o mesmo desenvolvimento quanto à melhoria do processo de projeto. No entanto, estudos têm demonstrado que a busca pela melhora da Construção Civil deve passar, necessariamente, por uma análise mais abrangente através do Processo de Desenvolvimento de Produto - PDP e de projeto (CODINHOTO, 2003; NOBRE, 2005).

Alguns autores, como Ballard e Koskela (1998), têm estudado a gestão do processo de projeto, indicando que na visão tradicional prevalecem o caos e a improvisação no planejamento e controle do processo de projeto. Como consequência, resulta em falhas de comunicação, falta de informações, ausência de coordenação entre as diferentes disciplinas (compatibilização) e erros nas tomadas de decisão (MANZIONE, 2013).

Enquanto o processo de projeto é um refinamento de soluções para um conjunto de problemas e uma progressiva eliminação de incertezas, a construção é a criação de um produto que precisa estar totalmente livre de incertezas (MITCHELL et al., 2011). Sob essa perspectiva, o projeto deve ser encarado como informação, seja de natureza técnica (definição do produto, materiais, indicações de detalhes construtivos e o próprio projeto como produto) ou como apoio ao processo gerencial, planejamento e programação da obra (OLIVEIRA, 2004). O processo interativo das equipes contribuirá para a redução de incertezas ao longo do projeto (MITCHELL et al., 2011).

Esse contraste de características cíclicas e lineares produz uma importante interface na complexidade do gerenciamento entre o processo de projeto e o processo construtivo. Também torna difícil a seleção de uma única ferramenta para lidar com ambos os planejamentos, não sendo possível estender o uso de técnicas de planejamento tradicional para o processo de projeto (MITCHELL et al., 2011). Consequentemente, o tipo de controle apropriado para o projeto não é o mesmo que o tipo de controle apropriado para a construção (BALLARD, 1999).

O setor de construção confronta-se com um processo de produção complexo e singular, com diferentes agentes envolvidos que mantêm uma atuação fragmentada e interesses próprios, e muitas vezes divergentes quanto às características e objetivos do empreendimento (OLIVEIRA, 2004; FABRÍCIO, 2002). Esses empreendimentos complexos e com multi-interesses alteram profundamente a dinâmica da relação entre projeto e construção e a gestão das atividades entre os dois (ANDERSEN et al., 2005).

Sob um ponto de vista contratual, a divisão do desenvolvimento do produto em fases é utilizada para tornar mais fácil a definição dos papéis e responsabilidades dos diferentes atores em um projeto, porém, distancia projetistas da obra (ANDERSEN et al., 2005). Além disso, esse cenário de segmentação e fragmentação entre o projeto e a produção prejudica a comunicação e o desenvolvimento do produto (JORGENSEN, 2006) e a divisão de um empreendimento em fases, que sem uma integração correta e sem uma visão holística, pode ser improdutiva (BALLARD; KOSKELA, 1998). Isto significa que a integração entre as diferentes partes envolvidas na construção pode melhorar a qualidade do projeto, agregando valor e eliminando perdas. 
Nos empreendimentos do mercado imobiliário, os atores envolvidos no desenvolvimento do projeto e na execução da construção normalmente trabalham em organizações diferentes, e o grupo das empresas que cooperam entre si varia de um empreendimento para o outro (OLIVEIRA, 2004). Em geral, a ligação entre essas organizações se desfaz após a conclusão do projeto, caracterizando-a como relações temporárias (ROMANO, 2003). Portanto, a equipe do projeto é composta de uma relação menos hierárquica e mais horizontal (ORIHUELA; ORIHUELA; ULLOA, 2011). Pelo envolvimento de várias empresas no desenvolvimento do projeto, a complexidade do processo de projeto aumenta e sua coordenação se torna ainda mais difícil (MOURA, 2005).

Na visão de projeto tradicional, a gestão de tarefas é priorizada, ou seja, as atividades de conversão são priorizadas (BALLARD; KOSKELA, 1998). Observa-se, então, que essas práticas utilizadas na gestão e no planejamento de projetos se restringem, na maioria das vezes, apenas ao controle de contratos e entregas de desenhos (MANZIONE, 2013). Nascimento et al. (2012) ressaltam que, ao se desconsiderar o contexto da organização, pode haver uma diminuição na transparência, um aumento da complexidade do processo ou a geração de buscas por informações (movimentação). Isso reduz a simplicidade do processo e incrementa a quantidade de atividades que não agregam valor.

A partir de uma abordagem holística, é natural aplicar o pensamento enxuto para todas as fases de um empreendimento, desde a concepção e construção até o uso e a manutenção (BALLARD; KOSKELA, 1998). Isso também deve ocorrer quanto aos processos de projeto. Contudo, apesar da disseminação da produção enxuta entre as empresas de construção, o Lean Project Delivery System (em particular, o lean design) é pouco conhecido. De fato, a implantação do pensamento enxuto é complexa e demorada. A integração entre as diferentes partes envolvidas na construção melhora a qualidade do projeto quando agrega valor e elimina desperdícios.

Isso nos leva a um modelo que extrapola a divisão tradicional em fases do processo de desenvolvimento do produto na construção civil. Elaborar um projeto utilizando o conceito Lean inclui a incorporação de diferentes ferramentas ou métodos de trabalho, que são pensados para aumentar a produtividade e/ou a qualidade do projeto. Algumas das ferramentas que poderiam ser inovadoras na indústria da construção são Integrated Project Delivery (IPD) e Building Information Modeling (BIM) (KAMEDULA, 2009).

Tais conceitos ainda não foram implementados na maioria das indústrias de construção. O que seria interessante explorar é se esses conceitos tornam o processo de trabalho mais eficiente e as vantagens e desvantagens no uso de tais métodos (KAMEDULA, 2009).

A percepção da necessidade de integração entre projeto e produção na construção civil tem ganhado maior atenção (TRESCASTRO, 2005). A partir da década de 90, o setor da construção civil passa a incluir ferramentas computacionais de projeto através de softwares CAD. O uso desses sistemas aumentou a precisão do desenho e facilitou a manipulação, representação e criação de alternativas, permitindo a experimentação de formas arquitetônicas mais complexas e ganhos na compatibilização de projetos (KOWALTOWSKI et al., 2006). Contudo, não se pode afirmar que tenha ocorrido uma mudança fundamental na projetação a partir dessa substituição das pranchetas por computadores (CELANI, 2003).

Ferramentas computacionais avançadas de visualização, juntamente com os princípios do pensamento enxuto, combatem desperdícios no processo de projeto, como a não observação aos requisitos dos clientes, a falta de coordenação interdisciplinar e indisponibilidade de informações (NASCIMENTO et al., 2012).

Nessa ótica, também se analisa a implantação da plataforma BIM nos escritórios de projeto e sua efetiva mudança nos métodos de projeto e nas 
relações entre as partes envolvidas dentro de um contexto de transição da plataforma anterior (CAD). A percepção dos profissionais ligados diretamente à produção de edificações é necessária para adaptação ao novo cenário de implantação de sistemas BIM. Essa nova tecnologia, diferente dos sistemas CAD, não se trata apenas de uma forma de representação, que ocorre posteriormente às atividades de criação. Apesar dos claros potenciais, a implantação do BIM também traz novos desafios à medida que modifica a própria dinâmica de projetar (ROMCY, 2012).

De acordo com Manzione (2013), ainda falta conhecimento sobre a integração da nova tecnologia na melhoria do processo de projeto e um novo paradigma para o trabalho colaborativo em projeto precisa ser adotado para incorporar a tecnologia BIM. Falta uma visão geral e uma compreensão abrangente de fatores não tecnológicos, tais como as relações e interdependências na intersecção entre a gestão do processo de projeto e o BIM.

Se implantado de maneira adequada, o BIM facilitará a integração entre o processo de projeto e o processo da construção, resultando na melhora da qualidade do produto (empreendimento), além da redução dos custos e do tempo de produção (SACKS et al., 2009). Além disso, com a migração para a plataforma BIM, há uma melhora na comunicação entre a equipe do projeto e exige-se uma mudança no processo de trabalho entre projetistas e construtores (GERBER; BECERIK-GERBER; KUNZ, 2010).

O objetivo principal deste trabalho é descrever como os projetistas e construtores avaliam o processo de projeto imobiliário, a fim de melhorar a compreensão de suas expectativas e necessidades. A percepção dos profissionais ligados diretamente à produção de edificações é necessária para a identificação das mudanças que o setor deve implementar para um melhor processo de desenvolvimento de produto, requerendo novas visões quanto ao processo de projeto (lean design). Como resultado, foram identificadas oportunidades de melhoria do processo de desenvolvimento de produto imobiliário. Essas oportunidades são indicadas com base na compreensão das necessidades e expectativas dos profissionais associados à concepção e execução de unidades de produtos de construção.

\section{MÉTODO}

Foi adotado como método de pesquisa a Survey visando ampliar a obtenção de dados do mercado imobiliário da cidade de Fortaleza, Ceará, com profissionais representantes de um grande número de empresas e, assim, obter um panorama da atual avaliação do processo de projeto entre construtores e projetistas, comparando com aqueles que migraram para plataforma BIM. A aplicação foi escolhida tendo em vista que se pretende investigar o grau de satisfação quanto ao processo e planejamento de projetos, quais expectativas de mudanças e se existem divergências entre projetistas e construtores-incorporadores.

Este trabalho é considerado exploratório, por adquirir uma visão macro sobre um fenômeno, e descritiva, por ser dirigida ao entendimento das diferentes visões entre os respondentes. As questões foram divididas em duas grandes seções: a primeira com informações acerca do perfil dos respondentes; e a segunda com questões sobre o processo de projeto e seu planejamento. Foi realizado um pré-teste para validação das perguntas e, após as revisões necessárias, foi formulado um questionário final.

Foram selecionados escritórios de projeto e empresas de construção civil que estão envolvidos na concepção e construção de edifícios verticais multifamiliares. Os projetistas de arquitetura foram mapeados pelo registro na ASBEA (Associação Brasileira dos Escritórios de Arquitetura), e as empresas de construção foram selecionadas através do registro no Inovacon 
(Programa de Inovação da Indústria da Construção) e na Coopercon (Cooperativa de Construção do Ceará). Assim, os escritórios de projeto que responderam ao questionário representam 36\% dos filiados à ASBEA, enquanto $20 \%$ das incorporadoras e construtoras são filiadas à Coopercon. Os escritórios de projeto de cálculo estrutural e instalações foram identificados e selecionados a partir das obras visitadas.

Os questionários, preenchidos por arquitetos e engenheiros, foram divididos em dois grupos: construtores (com 22 questões) e projetistas (com 24 questões). Haviam questões fechadas, utilizando a escala de Likert com sete níveis (Tabelas 2 e 3), incluindo o nível neutro, no qual o respondente nem estava satisfeito, nem insatisfeito; perguntas fechadas com escolha de mais de uma opção (gráficos 1 a 6), e questões abertas. As respostas das questões abertas foram analisadas agrupando respostas por temas correspondentes, tais como: prazo, relações e tecnologia (ver Quadro 01).

A pesquisa teve duração de nove meses (novembro/2013 a julho/2014), desde a montagem das perguntas até seu relatório final. Os questionários foram aplicados em 13 empresas incorporadoras e construtoras e em 17 escritórios de projeto, perfazendo um total de 89. Desse total, 22 foram respondidos em obras e 68 em escritórios de projeto. Esses números referem-se àqueles que retornaram à survey, havendo uma taxa de retorno de $80 \%$. Ressalta-se que os questionários foram entregues em cada local de aplicação em formato impresso para posterior coleta. Percebeu-se que, com essa ação, houve um aumento na taxa de retorno comparando-se com outros trabalhos, como por exemplo Cendón; Ribeiro e Chaves (2014). Na Tabela 1, podemos verificar um resumo do perfil dos respondentes, entre projetistas e construtores, cujas respostas serão comparadas no item Resultados.

Tabela 1. Perfil das organizações e dos profissionais respondentes.

\begin{tabular}{lcll|c|}
\hline \multicolumn{1}{|c|}{ Tipo de Organização } & Quantidade & \multicolumn{1}{c|}{ Tipo de profissional } & Quantidade \\
\hline Escritório de Arquitetura & 09 & Arquiteto & 29 \\
Escritório de Paisagismo & 02 & Eng. Projetista & 14 \\
Cálculo Estrutural & 02 & Téc. Projetista & 19 \\
Instalações & 03 & Eng. Obra & 25 \\
Ambientação $\left(^{*}\right)$ & 02 & Design de interiores & 01 \\
Incorporadora e Construtora & 13 & Agrônomo & 01 \\
TOTAL & 31 & & 89 \\
\hline
\end{tabular}

Fonte: Elaborado pelos autores. $\left({ }^{*}\right)$ Um dos escritórios de arquitetura também fazia ambientação.

\section{RESULTADOS}

Os dados dos questionários foram tabulados e gerados tabelas e gráficos que serão apresentados a seguir. Os escritórios de projeto possuem portes diferentes, tendo uma média de oito funcionários. Apenas três estavam acima dessa faixa, com: 34 colaboradores (arquitetura); 23 colaboradores (cálculo estrutural), e 26 colaboradores (instalações). As perguntas aplicadas eram semelhantes em escritórios de projeto e obras, de forma que fosse possível uma posterior comparação das respostas entre os dois grupos. A compilação das respostas para as questões fechadas, utilizando a escala de Likert, pode ser encontrada nas Tabelas 2 e 3 a seguir. 
Tabela 2. Nível de satisfação dos escritórios de projeto com o processo de projeto.

\begin{tabular}{|c|c|c|c|c|c|c|c|}
\hline Grau de satisfação com: & EX (\%) & MS (\%) & SF (\%) & NT (\%) & PC (\%) & MP (\%) & ND (\%) \\
\hline $\begin{array}{l}\text { Planejamento do } \\
\text { processo de projeto } \\
\text { atual de seus clientes? }\end{array}$ & 4,55 & 4,55 & 37,88 & 30,30 & 22,73 & 0,00 & 0,00 \\
\hline $\begin{array}{l}\text { Planejamento do } \\
\text { processo de projeto do } \\
\text { escritório? }\end{array}$ & 4,35 & 14,49 & 47,83 & 10,14 & 13,04 & 10,14 & 0,00 \\
\hline $\begin{array}{l}\text { Interesse do escritório } \\
\text { em adotar novas } \\
\text { práticas e ferramentas } \\
\text { para o planejamento e } \\
\text { controle do processo de } \\
\text { projeto? }\end{array}$ & 13,24 & 54,41 & 20,59 & 7,35 & 1,47 & 1,47 & 1,47 \\
\hline $\begin{array}{l}\text { As soluções adotadas } \\
\text { no projeto para etapa de } \\
\text { produção (execução da } \\
\text { obra)? }\end{array}$ & 11,76 & 20,59 & 39,71 & 17,65 & 8,82 & 1,47 & 0,00 \\
\hline $\begin{array}{l}\text { A precisão dos desenhos } \\
\text { e informações contidas } \\
\text { nos projetos realizados } \\
\text { pelo escritório? }\end{array}$ & 14,71 & 32,35 & 47,06 & 4,41 & 1,47 & 0,00 & 0,00 \\
\hline $\begin{array}{l}\text { A compatibilização dos } \\
\text { projetos desenvolvidos } \\
\text { pelo escritório com as } \\
\text { outras disciplinas do } \\
\text { projeto? }\end{array}$ & 5,88 & 20,59 & 42,65 & 11,76 & 10,29 & 7,35 & 1,47 \\
\hline $\begin{array}{l}\text { Entregas por etapas dos } \\
\text { projetos desenvolvidos } \\
\text { pelo escritório? }\end{array}$ & 5,88 & 27,94 & 42,65 & 16,18 & 7,35 & 0,00 & 0,00 \\
\hline $\begin{array}{l}\text { O fluxo de informações } \\
\text { entre o escritório e os } \\
\text { contratantes? }\end{array}$ & 3,03 & 13,64 & 39,39 & 24,24 & 15,15 & 4,55 & 0,00 \\
\hline $\begin{array}{l}\text { O fluxo de informações } \\
\text { entre o escritório e os } \\
\text { demais escritórios? }\end{array}$ & 1,49 & 13,43 & 34,33 & 22,39 & 16,42 & 10,45 & 1,49 \\
\hline $\begin{array}{l}\text { Transmissão de } \\
\text { informação durante as } \\
\text { etapas de projeto no } \\
\text { escritório? }\end{array}$ & 4,41 & 14,71 & 42,65 & 23,53 & 11,76 & 2,94 & 0,00 \\
\hline $\begin{array}{l}\text { Prazos estabelecidos } \\
\text { pelo cliente? }\end{array}$ & 1,47 & 7,35 & 29,41 & 32,35 & 23,53 & 1,47 & 4,41 \\
\hline $\begin{array}{l}\text { O projeto não inicia } \\
\text { sem que as restrições } \\
\text { de projeto tenham sido } \\
\text { removidas (entrada de } \\
\text { informação). }\end{array}$ & 3,13 & 3,13 & 34,38 & 26,56 & 17,19 & 9,38 & 6,25 \\
\hline
\end{tabular}

Fonte: Elaborado pelos autores. EX: extremamente, MS: muito satisfeito, SF: satisfeito, NT: neutro, PC: pouco, MP: muito pouco, ND: nada.

Analisando-se os percentuais de graus de satisfação dos entrevistados dos escritórios de projeto, as questões que obtiveram os mais altos níveis de insatisfação foram quanto à remoção de restrições $(32,82 \%)$ e prazos estabelecidos pelo cliente $(29,41 \%)$. Destacamos as questões que foram avaliadas positivamente pelos projetistas: precisão de desenhos e informações contidos nos projetos realizados pelo escritório de projeto 
(94,12\%) e interesse do escritório de projeto em adotar novas práticas e ferramentas para planejamento e controle do processo de projeto $(88,24 \%)$. Neutro foi considerado nem satisfeito nem pouco satisfeito.

Quanto à satisfação com o fluxo de informações entre escritório e as empresas contratantes (construtoras-incorporadoras), os projetistas BIM tiveram um grau de satisfação menor que os demais projetistas, demonstrando maior maturidade referente à outras visões do processo de projeto.

Esperava-se que projetistas usuários da plataforma BIM tivessem uma avaliação melhor quanto às soluções de projeto adotadas considerando a perspectiva de execução da obra, pois o BIM requer a definição de materiais, sistemas e detalhes construtivos para modelagem correta da edificação. Contudo, não houve diferença significativa quando comparado ao total de projetistas respondentes. Além disso, apesar de projetistas mostrarem um percentual em torno de $70 \%$ satisfeitos a extremamente satisfeitos, os construtores apresentaram grau de satisfação de 45,83\%. Assim, podemos afirmar que ainda há uma lacuna quanto ao feedback entre projetistas e construtores e pouca colaboração entre as partes envolvidas nos processos de projeto e construção.

Tabela 3. Nível de satisfação dos construtores com o processo de projeto.

\begin{tabular}{|c|c|c|c|c|c|c|c|}
\hline Grau de satisfação com: & EX (\%) & MS (\%) & SF (\%) & NT (\%) & PC (\%) & MP (\%) & ND (\%) \\
\hline $\begin{array}{l}\text { O atual planejamento } \\
\text { do processo de projeto } \\
\text { de construtora/ } \\
\text { incorporadora. }\end{array}$ & 4,17 & 8,33 & 41,67 & 4,17 & 33,33 & 4,17 & 4,17 \\
\hline $\begin{array}{l}\text { O atual planejamento } \\
\text { do processo de projeto } \\
\text { dos projetistas. }\end{array}$ & 0,00 & 4,17 & 25,00 & 8,33 & 37,50 & 12,50 & 12,50 \\
\hline $\begin{array}{l}\text { Interesse em adotar } \\
\text { novas práticas e } \\
\text { ferramentas de } \\
\text { planejamento e } \\
\text { controle do processo } \\
\text { de projeto. }\end{array}$ & 17,39 & 60,87 & 21,74 & 0,00 & 0,00 & 4,35 & 0,00 \\
\hline $\begin{array}{l}\text { As soluções de } \\
\text { projeto adotadas } \\
\text { na perspectiva da } \\
\text { execução da obra. }\end{array}$ & 0,00 & 0,00 & 45,83 & 12,50 & 25,00 & 12,50 & 4,17 \\
\hline $\begin{array}{l}\text { Precisão das } \\
\text { informações contidas } \\
\text { nos desenhos e } \\
\text { projetos realizados } \\
\text { pelos projetistas. }\end{array}$ & 0,00 & 0,00 & 45,83 & 12,50 & 16,67 & 16,67 & 8,33 \\
\hline $\begin{array}{l}\text { Compatibilização dos } \\
\text { projetos. }\end{array}$ & 0,00 & 0,00 & 20,83 & 20,83 & 33,33 & 16,67 & 8,33 \\
\hline $\begin{array}{l}\text { Entregas por } \\
\text { etapas dos projetos } \\
\text { desenvolvidos pelos } \\
\text { projetistas. }\end{array}$ & 0,00 & 4,17 & 29,17 & 16,67 & 37,50 & 8,33 & 4,17 \\
\hline $\begin{array}{l}\text { Fluxo de informações } \\
\text { entre os escritórios } \\
\text { de projetos e } \\
\text { a construtora/ } \\
\text { incorporadora. }\end{array}$ & 0,00 & 4,35 & 39,13 & 17,39 & 26,09 & 8,70 & 4,35 \\
\hline
\end{tabular}


Tabela 3. Continuação...

\begin{tabular}{l|c|c|c|c|c|c|c|}
\hline Grau de satisfação com: & EX (\%) & MS (\%) & SF (\%) & NT (\%) & PC (\%) & MP (\%) & ND (\%) \\
\hline $\begin{array}{l}\text { Disponibilização } \\
\text { de informações do }\end{array}$ & 0,00 & 16,67 & 37,50 & 20,83 & 16,67 & 0,00 & 8,33 \\
processo de projeto & & & & & & & \\
em um local de fácil & & & & & & \\
acesso na empresa \\
(fluxos, cronogramas,
\end{tabular}

Fonte: Elaborado pelos autores. EX: extremamente, MS: muito satisfeito, SF: satisfeito, NT: neutro, PC: pouco, MP: muito pouco, ND: nada.

Analisando-se os percentuais de graus de satisfação dos respondentes nas obras, as questões que obtiveram os mais altos níveis de insatisfação foram planejamento do processo de projeto dos escritórios de projeto $(62,50 \%)$ e compatibilização dos projetos (58,33\%). Também destacamos as questões que foram avaliadas positivamente pelos engenheiros de obra: interesse da incorporadora/construtora em adotar novas práticas e ferramentas para o planejamento e controle do processo de projeto $(95,65 \%)$ e disponibilização de informações do processo de projeto $(54,17 \%)$.

Percebe-se divergência entre projetistas e construtores na avaliação quanto à compatibilização dos projetos e às soluções de projeto adotadas na perspectiva da execução da obra. Em ambos os casos, as respostas de projetistas mostraram satisfação, enquanto os executores expressaram insatisfação. Mais uma vez, esperava-se que projetistas BIM apontassem um grau de satisfação maior para compatibilização de projetos, porém, esta manteve o mesmo índice de aprovação de $70 \%$, aproximadamente, contra $20,83 \%$ de satisfação de construtores. Essa avaliação diferente, assim como o planejamento do processo de projeto, demonstra que a migração de plataformas de projeto (CAD - BIM) não está ocorrendo da forma esperada pela literatura, uma vez que as deficiências do processo de projeto permanecem.

Para identificar se os projetistas utilizavam algum sistema de planejamento e controle de processo de projeto e quais práticas são mais recorrentes, havia uma pergunta quanto às práticas utilizadas (questão 11). O resultado pode ser verificado no Gráfico 1. Esse gráfico também compara as respostas entre todos os projetistas e o resultado entre os projetistas que utilizam a plataforma BIM. O planejamento de curto prazo e matriz de responsabilidades são as práticas mais recorrentes pelos grupos respondentes. Contudo, percebe-se que entre os projetistas BIM há uma maior aplicação de práticas de gestão do processo de projeto e atenção aos desperdícios gerados com o retrabalho no processo de projeto.

A mesma questão foi aplicada para os construtores (Gráfico 2), sendo as três práticas mais citadas: planejamento de longo prazo (25,00\%), planejamento de médio prazo (20,83\%) e planejamento de curto prazo $(19,44 \%)$. Para os projetistas, o planejamento de curto prazo tem sido mais recorrente. 


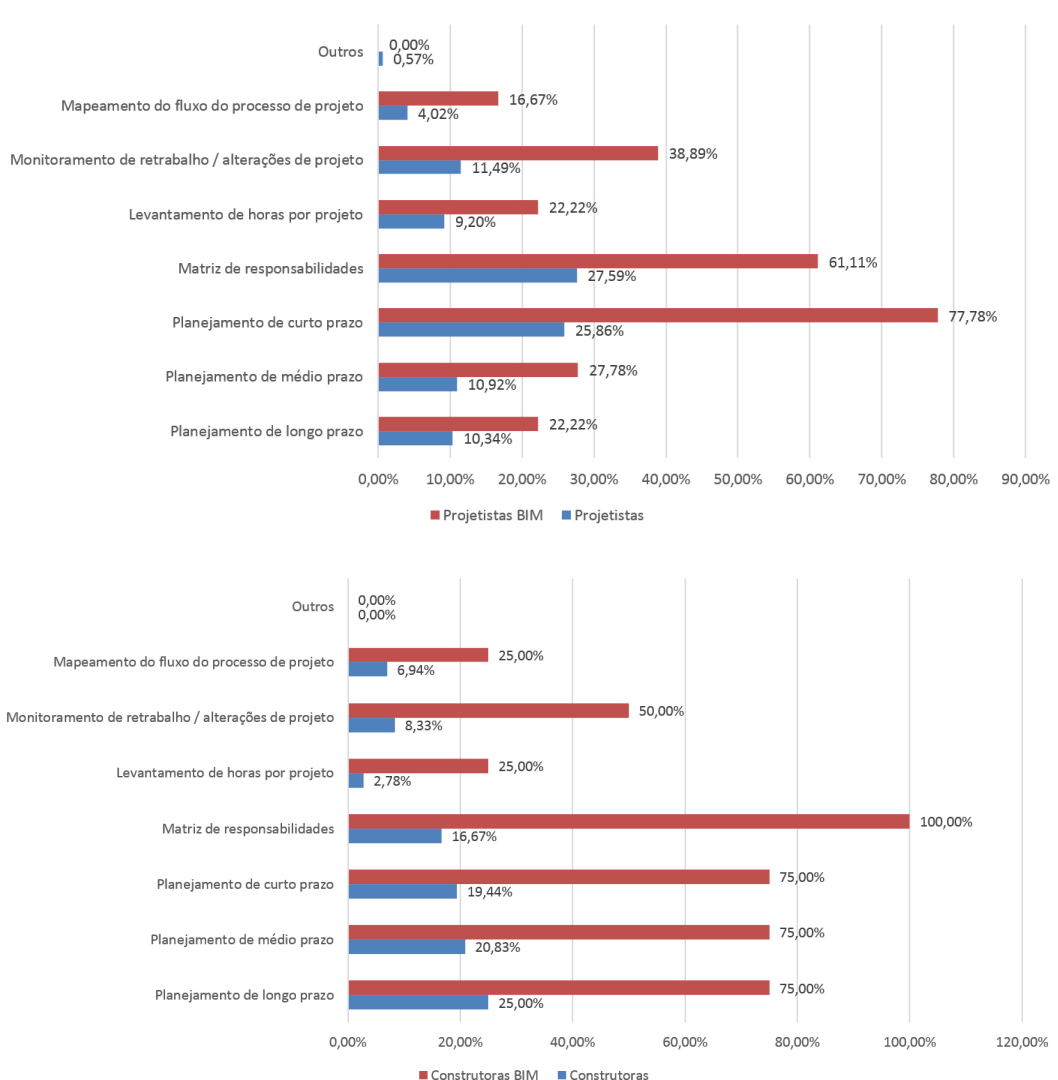

Havia uma questão a respeito dos softwares utilizados, com os seguintes resultados: $64,58 \%$ dos projetistas relataram o uso de CAD, enquanto $35,42 \%$ relataram o uso de BIM; $86,67 \%$ dos construtores usam CAD e 70,59\% utilizam o MS Project. Todos os escritórios de projeto de cálculo estrutural utilizam software BIM. Uma questão a ser observada é que o uso do BIM é limitado para os escritórios de arquitetura e cálculo estrutural, sendo pouco adotado por projetistas de instalações.

Foi aplicada entre os projetistas uma questão fechada com múltiplas respostas sobre o conhecimento ou familiaridade com os seguintes termos encontrados na literatura: construção enxuta/lean construction (41,51\%); gerenciamento de projetos (38,36\%); lean design (5,66\%); Project Management Institute (PMI) e Engenharia Simultânea (5,03\%, cada); Project Management Body of Knowledge (PMBOK) (4,40\%) e International Group for Lean Construction (IGLC) (1,89\%). Essa questão também foi respondida entre os construtores: construção enxuta/lean construction (47,47\%); gerenciamento de projetos (24,24\%); PMI (11,11\%); PMBOK (10,10\%); IGLC (5,05\%); lean design (2,02\%) e Engenharia Simultânea (0,00\%).

O processo de projeto na maioria dessas empresas é tradicional. Como consequência desta abordagem tradicional, temos uma execução ruim do projeto e falhas no desenvolvimento do produto, gerando perdas e retrabalho. Também há oportunidades para a melhoria sobre a adoção de engenharia simultânea, que é pouco conhecida pelos profissionais.

Também foram questionadas as razões pelas quais os projetistas e construtores estão interessados na adoção de novas práticas e ferramentas para o planejamento e controle do processo de projeto (Gráficos 3 e 4). Foram verificadas semelhanças nos dois grupos: há um aumento na qualidade dos projetos e redução de prazos. Porém, a principal razão apontada pelos construtores foi a redução de custos $(28,13 \%)$.
Gráfico 1. Práticas de planejamento e controle do processo de projeto (projetistas). Fonte: Elaborado pelos autores.

Gráfico 2. Práticas de planejamento e controle do processo de projeto usado em construtoras. Fonte: Elaborado pelos autores. 
Gráfico 3. Razões para adotar novas práticas e ferramentas para o planejamento e controle do processo de projeto (projetistas). Fonte: Elaborado pelos autores.

Gráfico 4. Razões para adotar novas práticas e ferramentas para o planejamento e controle do processo de projeto por construtores. Fonte: Elaborado pelos autores.

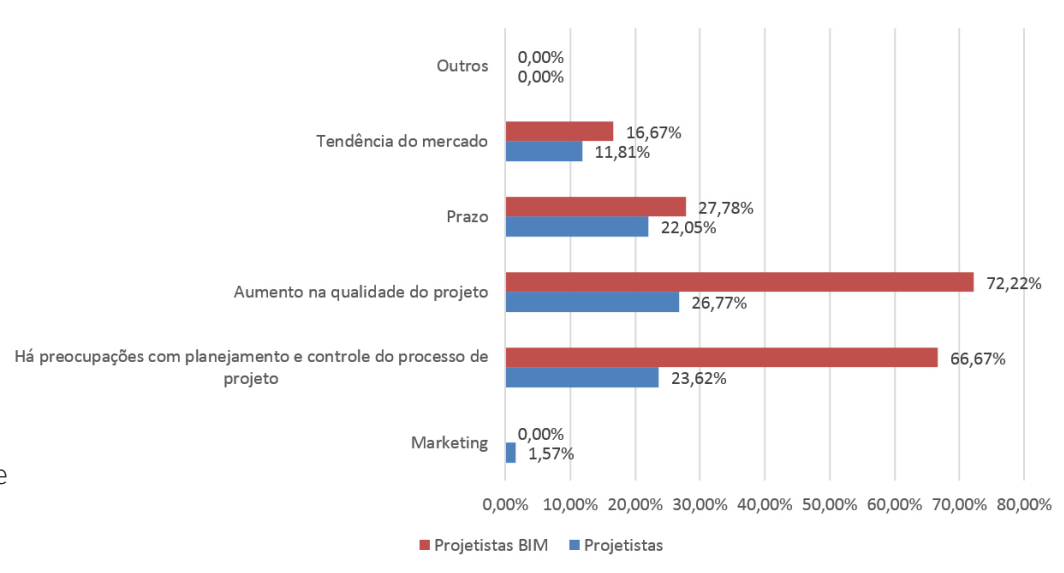

O número de projetistas em geral, os quais estavam extremamente interessados em adotar novas práticas e ferramentas de planejamento e controle do processo de projeto, foi menor entre respondentes $(13,24 \%)$ que o número de usuários da plataforma BIM (27,78\%). Estes fundamentaram sua posição no aumento da qualidade de projeto e do processo de projeto. Esse posicionamento nos leva a entender que no ambiente BIM há maior maturidade dos projetistas em relação ao processo de projeto.

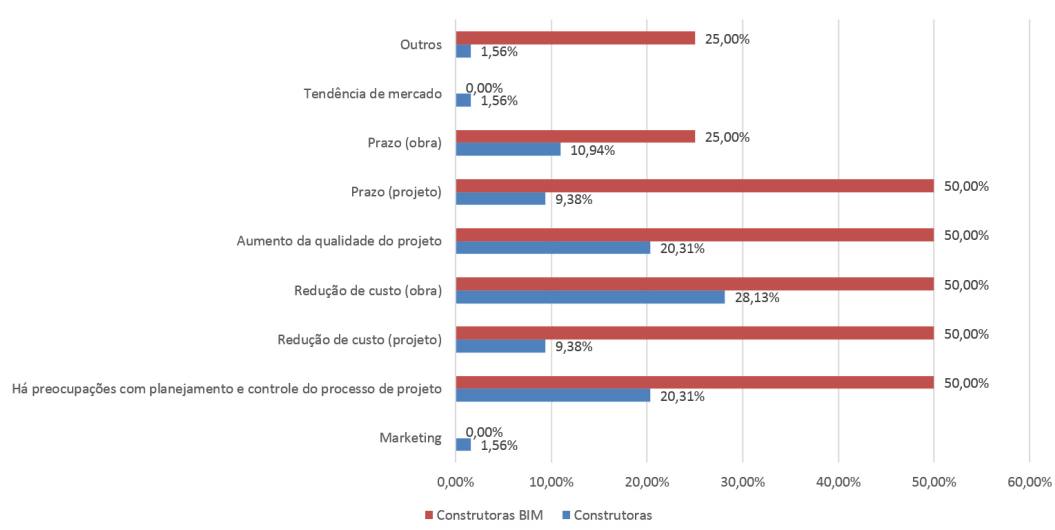

A questão aberta aplicada para ambos os grupos foi sobre os pontos positivos e negativos da metodologia de planejamento do processo de projeto das construtoras-incorporadoras (pergunta 9). Os resultados estão detalhados no Quadro 1.

Quadro 1. Avaliação da metodologia de planejamento do processo de projeto.

\begin{tabular}{|c|c|c|}
\hline & Projetistas & Construtores \\
\hline Positivo & $\begin{array}{l}\text { Relação de parceria entre a equipe e } \\
\text { abertura para novas soluções ( } 25 \% \text { ); } \\
\text { Transmissão de know-how } \\
\text { construtivo; valorização do detalhe } \\
\text { do projeto ( } 25 \% \text { ); } \\
\text { Organização de dados e } \\
\text { informações sobre o projeto } \\
\text { em plataformas on-line de } \\
\text { gerenciamento (18,75\%) } \\
\text { Pesquisa de mercado, frequência de } \\
\text { demanda de projetos, pró-atividade } \\
\text { para resolver problemas e questões } \\
\text { pendentes (18,75\%). }\end{array}$ & $\begin{array}{l}\text { Planejamento dos processos de } \\
\text { projeto e construção (26,67\%); } \\
\text { Análise crítica dos projetos (20\%); } \\
\text { Existe um departamento de } \\
\text { gerenciamento de projetos (13,33\%); } \\
\text { A integração da equipe (13,33\%); } \\
\text { Uso de novas tecnologias (13,33\%) }\end{array}$ \\
\hline
\end{tabular}


Quadro 1. Continuação...

\begin{tabular}{|c|c|c|}
\hline & Projetistas & Construtores \\
\hline \multirow{15}{*}{ Negativo } & Retrabalho (29,17\%); & \multirow[t]{2}{*}{ O prazo de entrega (37,5\%); } \\
\hline & Planejamento dos processos de & \\
\hline & projeto, a falta de processo de & \multirow[t]{4}{*}{ O planejamento do projeto (31,25\%); } \\
\hline & projeto interno nos escritórios e & \\
\hline & desorganização (20,83\%); & \\
\hline & Prazo (14,58\%); & \\
\hline & Compatibilização (12,50\%); & \multirow{4}{*}{ Compatibilização e revisão (12,50\%) } \\
\hline & Preferência por soluções padrão ou & \\
\hline & pouco inovadoras (8,33\%); & \\
\hline & Projetos com preços muito baixos; & \\
\hline & mudança de escopo; análise & \multirow{5}{*}{$\begin{array}{l}\text { A construção começa com o projeto } \\
\text { em andamento, falta de detalhe e } \\
\text { banco de dados de projetos (18,75\%) }\end{array}$} \\
\hline & baseada em corretor; requisitos das & \\
\hline & instituições de financiamento; falta & \\
\hline & de migração de software CAD para o & \\
\hline & $\operatorname{BIM}(10,42 \%)$ & \\
\hline
\end{tabular}

Fonte: Elaborado pelos autores

Um ponto negativo citado pelos projetistas foi a preferência por soluções padrão ou pouco inovadoras, contudo, os construtores afirmam a busca de novas tecnologias como um ponto positivo. Isso reforça uma tendência dos construtores de voltarem sua atenção às questões construtivas, enquanto questões de geração de valor, que são especificadas no projeto, são pouco exploradas, na visão dos projetistas.

Entre as dificuldades encontradas no processo de projeto nos escritórios de projeto (Gráfico 5), os mais citados foram: retrabalho em excesso (39,86\%) e cumprimento de prazos (26,81\%). A mesma questão (Gráfico 6), quando aplicada às empresas de incorporação e construção, obteve como principais itens o cumprimento de prazo (35\%) e compatibilização (33\%).

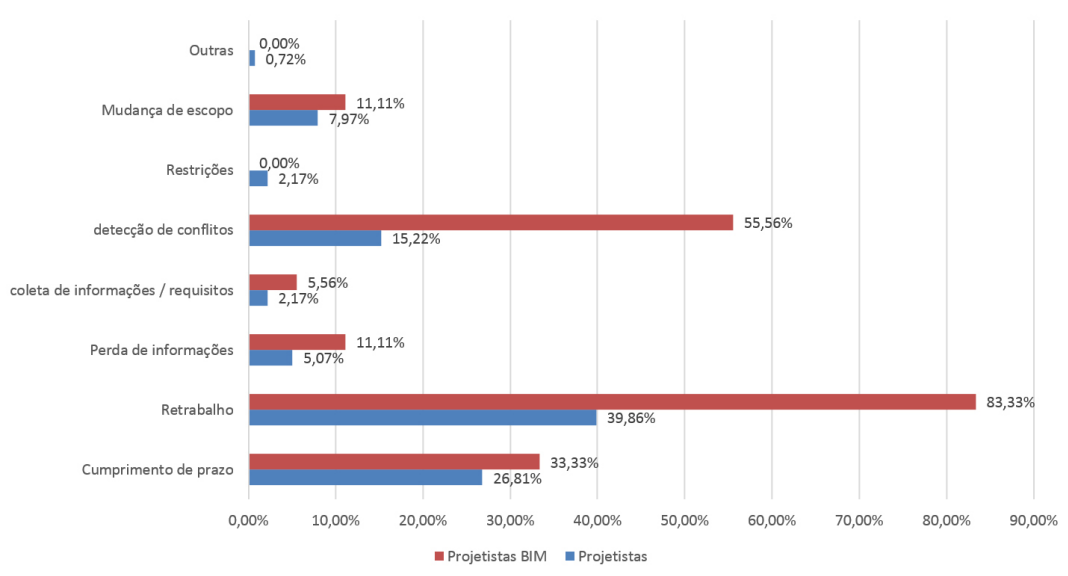

Gráfico 5. Dificuldades do processo de projeto em escritórios de projeto. Fonte: Elaborado pelos autores.

Os projetistas que utilizam a plataforma BIM mais uma vez demonstram maior entendimento dos fluxos no processo de projeto, apontando como pontos negativos as interações negativas (detecção de conflitos - 55,56\%; e retrabalho - 83,33\%) resultantes de um processo de projeto pouco convergente na busca de soluções no início da concepção, tais como a não identificação adequada de todas as interdependências, requisitos ou restrições de projeto. O mesmo se observa nas construtoras que utilizam plataforma BIM (ver Gráfico 6). 
Gráfico 6: Dificuldades do processo de projeto na construção. Fonte: Elaborado pelos autores.

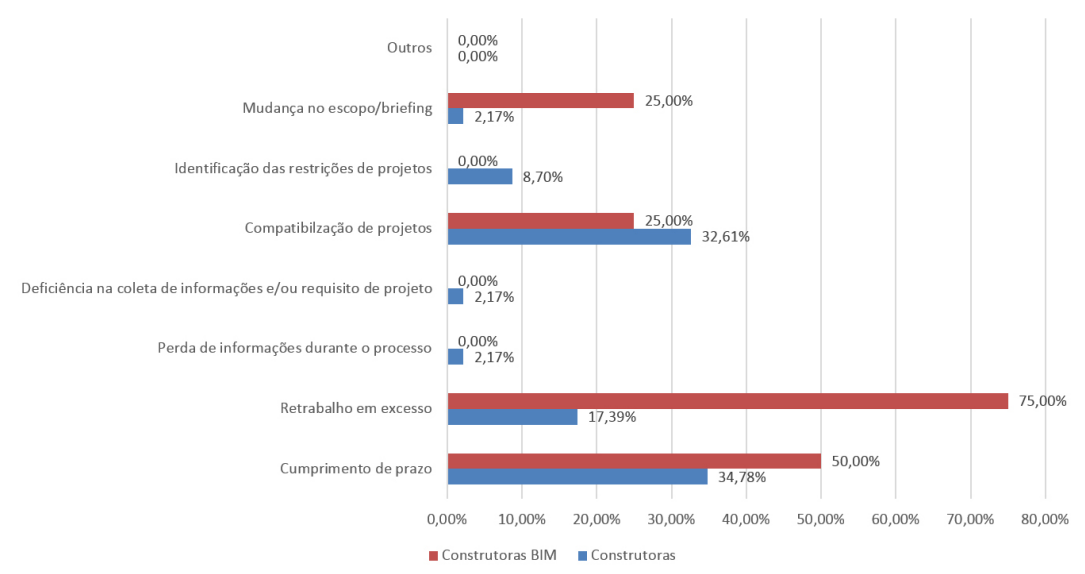

\section{CONCLUSÕES}

A presente pesquisa permitiu a avaliação do nível de satisfação de projetistas e construtores em relação ao processo de desenvolvimento de projetos do setor imobiliário residencial em Fortaleza/Ce. Entre os principais resultados obtidos no presente trabalho podemos destacar aqueles em que projetistas e construtores possuem graus de satisfação semelhantes e divergentes quanto ao processo e o planejamento do projeto imobiliário, sendo possível a comparação entre cada item. Ressalta-se que a amostra abrangeu $36 \%$ dos escritórios de arquitetura e 20\% das empresas incorporadoras e construtoras que atuam no segmento imobiliário, tendo respondidos todos os projetistas e parte dos engenheiros de obra das principais empresas de cada setor.

Oportunidades de melhoria e prioridades de intervenção foram identificadas a partir da análise descritiva das questões. Os dados obtidos mostram questões relevantes que permitem identificar a necessidade de ações que devem ser cumpridas pelos diversos atores envolvidos no produto imobiliário para que haja uma melhor integração do processo de projeto, evitando desperdícios e ampliando a geração de valor do produto.

Os principais problemas (insatisfação) identificados a partir da perspectiva de projetistas e construtores foram: retrabalho, falta de planejamento do processo de projeto, os prazos e compatibilização. Apesar de as novas visões do processo de projeto (conversão, fluxo e valor) serem conhecidas há algum tempo e o fato de que as empresas de construção adotam princípios da construção enxuta, percebe-se que o processo de projeto requer melhorias quanto à integração, o fluxo de informação e a geração de valor.

Mesmo com os diversos estudos ligados à qualidade do projeto e da construção, aumento de produtividade e integração, tais como construção enxuta, engenharia simultânea e Integrated Project Delivery (IPD), percebeuse, neste estudo, que as empresas de projeto e construção civil utilizam métodos deficientes de gestão de projetos, mesmo quando já migraram para a plataforma BIM ou para o sistema de produção enxuto, no qual se esperava uma mudança no processo projetual. Parte das deficiências ainda se pode atribuir à visão tradicional do processo de projeto, focando as atividades de conversão, desconsiderando os fluxos e a geração de valor no processo de projeto. Assim, há perdas resultantes da falta de informações, integração e colaboração da equipe de projeto, além da falta de inclusão dos construtores nessa equipe de concepção e de projetistas na equipe de execução, para elucidação de dúvidas e detalhamento, o que propiciaria um correto feedback da execução. 
Com este trabalho pode-se ter uma visão das deficiências do processo de desenvolvimento de produtos imobiliários, permitindo que os diversos atores e pesquisadores possam tomar ciência dos problemas apontados em busca de melhorias e novas formas de planejamento, integração e execução de projetos.

\section{REFERÊNCIAS}

ANDERSEN, J.; NYCYK, M.; JOLLY, L.; RADCLIFFE, D. Design management in a construction company. In: ICED 05 15TH INTERNATIONAL CONFERENCE ON ENGINEERING DESIGN: ENGINEERING DESIGN AND THE GLOBAL ECONOMY, 2005. Proceedings. Brisbane, 2005. p 2494.

BALLARD, G.; KOSKELA, L. On the agenda of design management research. In: PROCEEDINGS OF THE 6th ANNUAL CONFERENCE OF THE INTERNATIONAL GROUP FOR LEAN CONSTRUCTION, 1998 Guarujá. Proceedings... Guarujá, 1998. p. 52-69.

BALLARD, G. Can pull techniques be used in design management? In: PROCEEDINGS OF CONFERENCE ON CONCURRENT ENGINEERING IN CONSTRUCTION, 1999 Helsinki. Proceedings... Helsinque, 1999. p. 149-160.

CENDÓN, B. V.; RIBEIRO, N. A.; CHAVES, C. J. Pesquisas de survey: análise das reações dos respondentes. Informação \& Sociedade: Estudos, João Pessoa, v. 24, n. 3, p. 29-48, set./dez. 2014

CELANI, G. CAD criativo. São Paulo: Campus, 2003.

CODINHOTO, R. Diretrizes para o planejamento integrado dos processos de projeto e produção na construção civil. 2003. 176 f. Dissertação (Mestrado em Engenharia Civil) - Núcleo Orientado para a Inovação da Edificação, Programa de PósGraduação em Engenharia Civil, Escola de Engenharia, Universidade Federal do Rio Grande do Sul, Porto Alegre, 2003.

FABRICIO, M. M. Projeto Simultâneo na Construção de Edifícios. 2002. 329f Tese (Doutorado) - Escola Politécnica, Universidade de São Paulo, São Paulo, 2002.

GERBER, D.; BECERIK-GERBER, B.; KUNZ, A. Building Information Modelling and Lean Construction: technology, methodology and advances from practice. In: PROCEEDINGS OF THE 18TH CONFERENCE OF THE INTERNATIONAL GROUP OF LEAN CONSTRUCTION, 2010, Haifa. Proceedings... Haifa, 2010.

JØRGENSEN, B. Integrating lean design and lean construction: processes and methods. 2006. 286 f. Tese (Doutorado) - Departamento de Engenharia Civil, Universidade Técnica da Dinamarca, Dinamarca, 2006.

KAMEDULA, J. M. Lean Design. Copenhagen School of Design and Technology, 2009 Disponivel em: <http://www.kamedula.dk/ Johan/Lean_Design.pdf>. Acesso em: 13 out. 2015.

KOWALTOWSKI, D. C. C. K.; CELANI, M. G. C.; MOREIRA, D. C.; PINA, S. A. M. G.; RUSCHEL, R. C.; SILVA, V. G.; LABAKI, L. C.; PETRECHE, J. R. D. Reflexão sobre metodologias de projeto arquitetônico. Ambiente construído, Porto Alegre, v. 6, n. 2, p. 7-19, abr./jun. 2006.

MANZIONE, L. Proposição de uma estrutura conceitual de gestão do processo de projeto colaborativo com o uso do BIM. 2013. 353 f. Tese (Doutorado) - Escola Politécnica, Universidade de São Paulo, São Paulo, 2013.

MITCHELL, A.; FRAME, I.; CODAY, A.; HOXLEY, M. A conceptual framework of the interface between the design and construction processes. Engineering, Construction and Architectural Management, v. 18, n. 3, p. 297-311, 2011. DOl: http://dx.doi. org/10.1108/09699981111126197.

MOURA, P. M. Um estudo sobre a coordenação do processo de projeto em empreendimentos complexos. 2005 179 f. Dissertação (Mestrado) - Programa de Pós-Graduação em Engenharia Civil, Universidade Federal do Rio Grande do Sul, Porto Alegre, 2005

NASCIMENTO, E. L.; BIZ, A. A.; FREITAS, M. C. D.; SCHEER, S. Modelagem de informações no desenvolvimento enxuto de projetos. In: SALGADO, M. S.; RHEINGANTZ, P. A.; AZEVEDO, G. A. N.; SILVOSO, M. M. Projetos complexos e seus impactos na cidade e na paisagem. Rio de Janeiro: UFRJ/FAU/PROARQ; ANTAC, 2012.

NOBRE, J. A. P. Proposição de melhorias no processo de desenvolvimento de produto da construção civil mediante a captação das informações dos clientes. 2005. Dissertação (Mestrado) - Curso de Mestrado Profissional em Administração, Universidade Federal do Ceará, Fortaleza, 2005. 
OLIVEIRA, O. J. Gestão do processo de projeto na construção de edifícios. Integração, São Paulo, v. 38, p. 201-217, 2004.

ORIHUELA, P.; ORIHUELA, J.; ULLOA, K. Tools for design management in building projects. In: INTERNATIONAL GROUP FOR LEAN CONSTRUCTION IGLC 19, 2011, Lima. Proceedings... Lima, 2011. p. 427-436.

ROMANO, F. V. Modelo de referência para o gerenciamento do processo de projeto integrado de edificações. 2003. 326 f. Tese (Doutorado) - Programa de Pós-Graduação em Engenharia de Produção, Universidade Federal de Santa Catarina, Florianópolis, 2003.

ROMCY, N. M. S. Proposta de tradução dos princípios da coordenação modular em parâmetros aplicáveis ao building information modeling. 2012. $181 \mathrm{f}$. Dissertação (Mestrado) - Programa de PósGraduação em Engenharia Civil: Estruturas e Construção Civil, Universidade Federal do Ceará, Fortaleza, 2005.

SACKS, R.; DAVE, B.; KOSKELA, L. J.; OWEN, R. L. Analysis Framework for the Interaction between Lean Construction and Building
Information Modelling. In: INTERNATIONAL GROUP OF LEAN CONSTRUCTION IGLC 17, 2009, Taipei. Proceedings... Taipei, 2009. p. 221-34.

TRESCASTRO, M. G. Diretrizes para a segmentação e sequenciamento das atividades no processo de projeto em ambientes simultâneos na construção civil. 2005. 170 f. Dissertação (Mestrado) - Núcleo Orientado para a Inovação da Edificação, Programa de Pós-Graduação em Engenharia Civil, Universidade Federal do Rio Grande do Sul, Porto Alegre, 2005.

TZORTZOPOULOS, P. Contribuições para o desenvolvimento de um modelo do processo de projeto de edificações em empresas construtoras incorporadoras de pequeno porte. 1999. 150 f. Dissertação (Mestrado) - Universidade Federal do Rio Grande do Sul, Porto Alegre, 1999.

TZORTZOPOULOS, P.; FORMOSO, C. T. Considerations on Application of Lean Construction to Design Management. In: PROCEEDINGS FOR THE 7TH ANNUAL CONFERENCE OF THE INTERNATIONAL GROUP FOR LEAN CONSTRUCTION (IGLC7), 1999, Berkeley. Proceedings... Berkeley, 1999. p. 335-44.
Kelma Pinheiro Leite kelmapinheiro@yahoo.com.br José de Paula Barros Neto jpbarros@ufc.br

Marina Teixeira

marinacoelho.rt@gmail.com

Camila Claudino

camilaclaudino9@gmail.com 